INTERMIDIALIDADE NA FORMAÇÃO EM LETRAS

\title{
Intermediality and Learning
}

DOI: 10.14393/LL63-v37n1-2021-01

Thaïs Flores Nogueira Diniz*

RESUMO: O texto trata da substituição do título e conteúdo das disciplinas de Literatura Inglesa e Literatura norte-americana por Literaturas de expressão inglesa, disciplina com novos conteúdos e um outro título. Trata ainda da disciplina Introdução à Intermidialidade, de sua criação e das transformações a que se submeteu ao longo dos anos desde o seu surgimento. Discute o termo intermidialidade como ferramenta para análise de obras em língua inglesa, sejam elas canônicas ou não, compostas em países anglófonos. Por fim, sugere uma maneira de abordar essas obras, apresentando alguns exemplos de aulas e atividades da disciplina mencionada, oferecida em diferentes semestres, a alunos de Graduação provenientes de todas as unidades da universidade.

PALAVRAS-CHAVE: Intermidialidade. Ensino. Literatura. Shakespeare. William Blake. Niyi Osundare.

ABSTRACT: This text deals with the replacement of two disciplines (English Literature and North-American Literature) by another with a different title and a different content: Literatures in English. It also mentions a new discipline, Introduction to Intermediality, its creation and transformations undergone for years. It discusses the term intermediality as a tool for the analysis of works in English, canonical or not, produced in Anglophonic countries. Eventually it suggests a new way of dealing with those works, presenting some examples of classes and activities of the abovementioned discipline, offered in different terms, to undergraduate students from all units of the University.

KEYWORDS: Intermediality. Teaching. Literature. Shakespeare. William Blake. Niyi Osundare.

* Thaïs Flores Nogueira Diniz, Professora aposentada pela Universidade Federal de Minas Gerais. ORCID: 00000002-4726-8536. E-mail: tfndiniz(AT)terra.com.br 


\section{Introdução}

Até o século XIX, a língua inglesa era considerada como um monumento imutável e de posição invejável. Dando apoio a essa posição, Bernard Shaw escreveu a peça Pygmalion, que defendia a ideia de que era preciso falar a língua inglesa sem nenhum sotaque para pertencer à classe dominante na Inglaterra. A obra do dramaturgo inglês conta a história de Eliza Doolitle, uma pobre moça que vendia flores nas ruas de Londres. Um professor de fonética, ao ouvir o sotaque da moça, aposta com seu amigo que é capaz de transformar uma simples vendedora de flores numa dama da alta sociedade apenas ensinando-a a falar a língua correta e vence o desafio.

Um outro exemplo de que a língua protagonizava a divisão de classes era o "RP" (received pronunciation), cuja preocupação era com a pronúncia, também denominada de BBC English, (Standard British Pronunciation ou Southern English Pronunciation) mas que focava também na gramática, no vocabulário e na escrita. Dentro da Inglaterra, o maior grau de prestígio era associado a qualquer fala que não tivesse nenhum sotaque regional, já que se presumia que poder-se-ia determinar a região à qual o falante pertencia. Por décadas as mídias (o rádio e principalmente a TV) forneceram diariamente para toda a nação a fala dos que tinham posição de alto prestígio. Hoje a situação mudou e as sanções sociais contra as falas linguisticamente diferentes desapareceram. Pessoas com sotaques regionais ocupam posições de prestígio, o que enfraqueceu a velha associação de autoridade exclusivamente com sotaque não-regional.

Essa posição privilegiada da língua inglesa no mundo começou a ruir sob o peso do Imperialismo: a língua falada na BBC foi sendo substituída por variações mais ou menos distintas contra os quais não mais existe o preconceito. Muitas obras literárias, escritas nessas variações da língua inglesa, passaram a ser abordadas nos departamentos de literatura. São obras literárias de autores oriundos principalmente das colônias inglesas: peças teatrais da África do Sul, romances da Índia, poemas do Caribe, além de outras. O conhecimento dessas obras fez com que o estudo tradicional da chamada Literatura Inglesa passasse a ter outro foco acarretando assim uma transformação radical nos currículos escolares. Hoje, nas Faculdades de Letras, a disciplina que estuda muitas dessas obras - sejam elas canônicas ou 
não, escritas no Canadá, Caribe, Austrália, África, ou nos Estados Unidos e no Reino Unido - é denominada de Literaturas de expressão inglesa.

Por outro lado, Stephen Greenblat (1997, p. 13-15) questiona a validade dos estudos tradicionais compartimentalizados em disciplinas específicas e em departamentos estanques, afirmando que há o desejo de transcender limites disciplinares. O teórico aponta então a intermidialidade como um conceito (e também uma ferramenta de crítica) adotado hoje como meio de ligar o estudo de tais obras à crítica, ao pensamento estético e à própria prática artística. Assim, o estudo de obras ditas intermidiáticas vem ampliar e enriquecer os currículos dos cursos de Letras ao produzir uma concepção inovadora do potencial intermidiático entre a literatura e as artes e mídias. Segundo ele, promover estratégias críticas interdisciplinares é o desafio dos acadêmicos de hoje. Em consequência, a investigação sobre as relações entre texto e as outras artes e mídias torna-se inevitável.

A TV, o cinema, a música popular, as instalações, as imagens computadorizadas, a videoarte, a arte digital etc., derivam, como no teatro elizabetano, da interseção das artes e mídias (palavras, imagens, música, dança). São empreendimentos que dependem de criadores/artistas com diferentes especializações e que conversam entre si. Os estudiosos procuram valer-se dessas várias habilidades para compreender os objetos/produtos culturais contemporâneos: os filmes que os jovens assistem, os hipertextos que eles baixam na internet, as vídeo instalações que encontram nos museus e o tipo de performance do teatro de hoje. É preciso, portanto, haver uma interação inovadora com a tradição, para criar um movimento em direção a esse novo alinhamento intermidiático e híbrido.

O interesse pelo estudo de obras em língua inglesa em geral e sua associação com outros produtos culturais surgiu, portanto, sob a pressão desses novos alinhamentos culturais: obras menos anglocêntricas e o conceito de intermidialidade. Na Faculdade de Letras da UFMG, esse tipo de estudo já acontece desde o ano 2000, quando houve uma modificação radical no currículo do Curso de Letras, com a abolição dos Departamentos e a criação de muitas disciplinas dentro desses novos parâmetros. 


\section{Introdução à Intermidialidade}

Entre essas disciplinas, citamos a criação, após a visita do Prof. Claus Clüver ${ }^{1}$ em 2005, de uma que hoje é ofertada para todas as unidades da Universidade, a UNI 004: Introdução à Intermidialidade. Foi pensada pelos membros do Grupo de pesquisa ali formado, 0 Intermidia ${ }^{2}$, com o objetivo de introduzir um estudo que tentasse solucionar problemas de nomenclatura e agrupasse professores que tivessem, além de algo comum entre suas pesquisas, um novo olhar sobre as obras das Literaturas de expressão inglesa e também de outras línguas. A disciplina foi inicialmente oferecida em 2006 pelos professores do grupo que apresentaram aos alunos um relato de suas pesquisas. Foram convidados docentes que trabalhassem especificamente com a relação entre a literatura e as artes visuais, a música, o teatro e o cinema. Pensando na função e objetivos da disciplina e em quem seriam os ministrantes, passou-se a pensar nas configurações que seriam estudadas, em suas categorias e modos de interações e nos métodos a serem adotados. O "close reading"3, juntamente com uma abordagem semiótica, foram os métodos escolhidos para a investigação das interrelações entre essas configurações, por meio de análise, interpretação, paralelos e analogias, além da comparação e contraste entre elas.

A partir de 2009, a disciplina passou a ser oferecida em módulos, cada um tendo como responsável um professor de cada uma das áreas envolvidas: Letras, Belas Artes, Música e Comunicação. A ementa "iniciar os alunos no estudo das artes visuais, literatura, música e mídias, desenvolvendo neles competências básicas para a leitura e análise de obras em mídias variadas, bem como de suas combinações e interações" passou a nortear a disciplina que não mais dividiu as aulas por área e sim por processos. Inicialmente, os módulos contemplavam as categorias propostas por Leo $\mathrm{H}_{\text {. Hoek}}^{4}$, que tratava da classificação das relações possíveis

\footnotetext{
${ }^{1}$ Professor Emérito de Literatura Comparada pela Universidade de Indiana, Indiana, EUA. Mais informações disponíveis em: https://clacs.indiana.edu/about/faculty/cluver-claus.html.

2 Mais informações disponíveis em: http://www.letras.ufmg.br/nucleos/intermidia/ e http://dgp.cnpq.br/dgp/espelhogrupo/24246.

${ }^{3} \mathrm{Na}$ crítica literária, a leitura atenta é a interpretação cuidadosa e sustentada de uma breve passagem de um texto. Uma leitura atenta enfatiza o único e o particular sobre o geral, efetuados com muita atenção às palavras individuais, a sintaxe, a ordem em que as frases se desenrolam e as estruturas formais.

${ }^{4}$ Para Leo Hoek, a relação entre texto e imagem pode ser estudada sob duas perspectivas diferentes: sob o ponto de vista da produção, onde texto e imagem são marcados pela sucessividade e sob o ponto de vista da
} 
entre texto e imagem, relação que dependia da situação de comunicação relacionada tanto à produção quanto à recepção. Como a classificação de Hoek (2006) era muito detalhada, os módulos, a partir de 2010, passaram a usar as categorias propostas por Irina Rajewsky ${ }^{5}$, que eram mais simples e abrangiam praticamente todos os textos híbridos.

QUADRO 1: Disciplina Introdução à Intermidialidade UNI 004

\begin{tabular}{|c|c|}
\hline $\begin{array}{l}\text { Módulo } 1 \\
\text { Introdução }\end{array}$ & $\begin{array}{l}\text { Aula 1: Aspectos da intermidialidade: Imagem, combinação palavra/imagem } \\
\text { Aula 2: Transposição x Intermídia/música } \\
\text { Aula 3: Intermidialidade / intertextualidade/ intersemioticidade / estudos } \\
\text { interartes } \\
\text { Aula 4: Intertextualidade intermidiática }\end{array}$ \\
\hline $\begin{array}{l}\text { Módulo } 2 \\
\text { Fusão }\end{array}$ & $\begin{array}{l}\text { Aula 5: Textos e gêneros multimídia e mixmídias: cartaz, publicidade na TV, } \\
\text { selo postal, emblema, livro de artista, história em quadrinhos } \\
\text { Aula 6: Textos e gêneros multimídias, mixmídias e intermídias: } \\
\text { Aula 7: artes visuais e artes cênicas; "performance"; instalações; artes } \\
\text { plásticas e músicas; música eletrônica x palavras } \\
\text { Aula 8: Textos intermídias: poesia visual, poesia concreta, poesia sonora, } \\
\text { "carmina figurata", logotipos }\end{array}$ \\
\hline $\begin{array}{l}\text { Módulo } 3 \\
\text { Transposição } \\
\end{array}$ & $\begin{array}{l}\text { Aula 9: O papel do "leitor": écfrase e ilustração } \\
\text { Aula 10: A adaptação cinematográfica } \\
\text { Aula 11: Palavras nas imagens/imagens em textos verbais/pintores e pinturas } \\
\text { na literatura; Espaço/ tempo/ narratividade/ representação } \\
\text { Aula 12: Imitação genérica: o retrato, a fotonovela, a fuga e a paisagem }\end{array}$ \\
\hline $\begin{array}{l}\text { Módulo } 4 \\
\text { Intermidialidade } \\
\text { digital }\end{array}$ & $\begin{array}{l}\text { Aula 13: Adaptação e imitação entre mídias } \\
\text { Aula 14: colagem e montagem nas artes plásticas e em outras mídias } \\
\text { Aula 15: Midialidade e tecnologia: a criação de novas linguagens através de } \\
\text { novos meios de comunicação } \\
\text { Aula 16: vídeo e vídeo arte, poesia digital e biopoesia. }\end{array}$ \\
\hline
\end{tabular}

Fonte: elaborado pela autora.

recepção, onde texto e imagem são simultâneos ou imediatamente justapostos. Ele enfatiza a importância da distinção entre esses dois processos para a classificação das relações entre texto e imagem, utilizando critérios como a primazia da imagem, a primazia do texto ou a simultaneidade. HOEK, Leo. A transposição intersemiótica: por uma classificação pragmática. In: ARBEX, Márcia. Poéticas do visível. Belo Horizonte: Programa de PósGraduação em Estudos Literários, Faculdade de Letras, UFMG, 2006, p. 167-190. Disponível em: http://www.letras.ufmg.br/site/e-livros/Po\%C3\%A9ticas\%20do\%20vis\%C3\%ADvel\%20-

\%20ensaios\%20sobre\%20a\%20escrita\%20e\%20a\%20imagem.pdf. Acesso: 12 de nov. 2020.

${ }^{5}$ Para Irina Rajewsky, existem três categorias para classificar a relação entre texto e imagem: transposição, combinação e referência intermidiática. No primeiro caso, um texto desaparece para se tornar outro. No segundo caso, os dois textos se unem em um só. E no caso das referências intermidiáticas, há em um único texto a referência a outra mídia, porém o texto não perde a sua essência. RAJEWSKY, Irina. Intermidialidade, Intertextualidade e "remediação": uma perspectiva literária sobre a intermidialidade. Tradução de Thaïs Diniz e Eliana Lourenço Lima Reis. In: Diniz, Thaïs F. N. (Org.). Intermidialidade e estudos interartes: desafios da arte contemporânea. Belo Horizonte: Editora UFMG, 2012, p. 15-45. 
A ementa foi sofrendo algumas alterações e atualmente, ao contemplar processos e não apenas áreas, a disciplina continua sendo oferecida regularmente na UFMG, ainda em módulos, porém cada docente responsável por um módulo propõe análises de textos constituídos dentro das mais variadas mídias e interrelacionados de várias maneiras, procurando aliar o conceito de intermidialidade também ao estudo de obras não canônicas.

\section{Shakespeare e a Intermidialidade}

Um exemplo desse novo olhar sobre as obras das Literaturas de expressão inglesa é o estudo que se faz de Shakespeare. Como não temos ideia de como suas peças eram encenadas, temos de nos valer dos textos escritos que, por si só, não contam toda a história. As peças, como sabemos, não eram simplesmente lidas, mas assistidas no palco, momento em que a combinação das palavras e imagens, conjugadas, era recebida pelos espectadores. Por isso, é impossível considerar suas peças como conjuntos de palavras numa página desvinculados de qualquer outra forma de expressão já que outros fatores influenciaram a recepção (a encenação, a censura, o travestimento e os próprios figurinos).

Para ilustrar o estudo de Shakespeare sob essa nova perspectiva, descrevo as atividades de uma aula ministrada, dentro da disciplina UNI 004, baseada em um dos episódios de Hamlet que aguça a curiosidade dos alunos quando estudam essa peça. Este episódio relaciona-se à personagem Gertrudes que, embora seja uma figura central na peça, não se conhece realmente quais são seus sentimentos e motivações. Para Hamlet, ela teria se casado muito às pressas com o cunhado, mas não há, no texto, evidência de seu conhecimento sobre o assassinato do rei. Para aumentar ainda mais a curiosidade dos leitores, Shakespeare introduziu uma cena em que toda a Corte se reúne para assistir a uma peça de teatro, encomendada por Hamlet. Esta descrevia a forma como teria se dado um assassinato, muito semelhante ao que se presume tenha acontecido na Corte. Os espectadores de Shakespeare sabem ser este o plano de Hamlet para desmascarar o tio e, quem sabe, expor a possível culpa de Gertrudes. A questão que se põe é saber se a rainha tinha ou não conhecimento do que de fato acontecera, o que deixaria em dúvida sua culpa. As interpretações possíveis variam desde a completa inocência de Gertrudes até sua total culpa. 
Para discutir esse assunto, são apresentadas aos alunos duas pinturas famosas que ilustram perspectivas totalmente opostas do mesmo episódio - The Play Scene in Hamlet, de Daniel Maclise (Figura 1) e Hamlet, de Edwin Abbey (Figura 2).

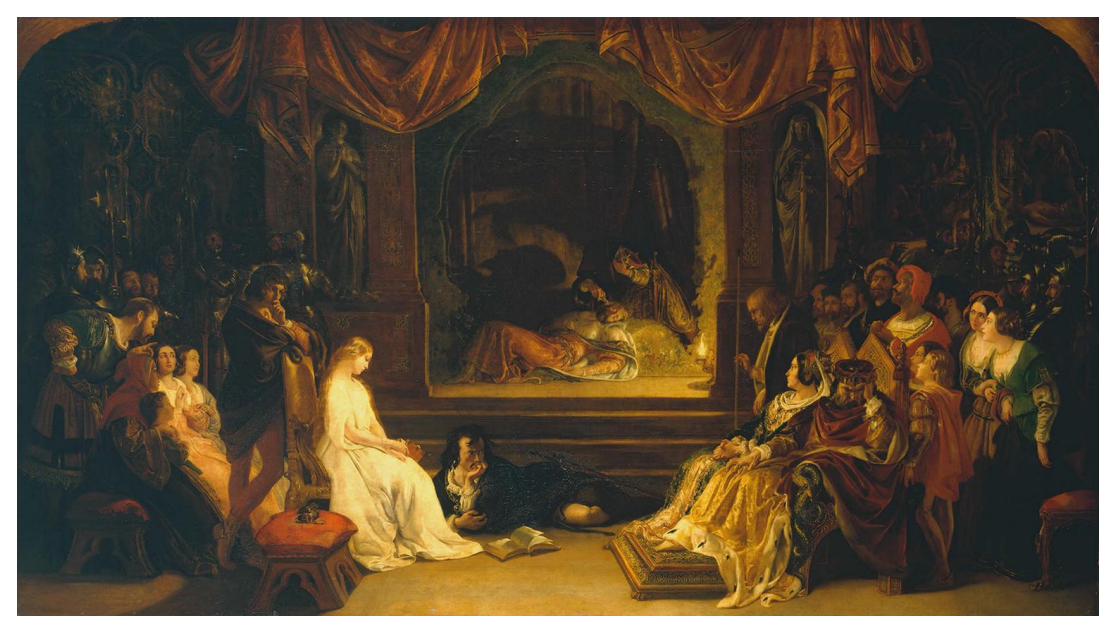

FIGURA 1: The Play Scene in Hamlet, de Daniel Maclise, (1842). Óleo sobre tela 60' x 108' - Tate Gallery, Londres, Reino Unido.

Fonte: https://www.tate.org.uk/art/artworks/maclise-the-play-scene-in-hamlet-n00422

Na pintura de Maclise (Figura 1), todos os personagens, exceto Hamlet e Horácio que têm o olhar fixo em Cláudio, olham para o palco ao fundo do quadro. Apesar da imagem de Caim e Abel ali exposta, da sombra aterrorizante na parede e da reação conturbada de Cláudio - elementos que poderiam causar desconforto numa Gertrudes culpada - ela se acha sentada serenamente, assistindo à peça, sem nenhuma expressão de angústia ou medo. Além disso parece não perceber o mal-estar do marido. A pintura, portanto, reflete a interpretação dos Românticos: uma Gertrudes inocente que não suspeita de Cláudio e nem do assassinato em si.

O desafio de Abbey (Figura 2) foi evitar duplicar a famosa pintura de Maclise. Sua solução foi inovadora. Os figurantes olham para fora do quadro, onde se espera que a encenação, fora do alcance visual do espectador, esteja acontecendo, enquanto Cláudio é observado por Hamlet. A ênfase então é dada à reação dos personagens, colocados no centro da pintura. Nesta obra, além da composição totalmente diferente, Gertrudes não se assemelha à mulher serena da tela de Maclise: ela se encontra afastada de Cláudio, encolhida 
num canto, escondendo o rosto sob um véu negro. Sua reação e a distância interposta entre ela e o marido sugerem estar ela a par do significado da peça a que assistem. O artista deixa, portanto, indícios de uma Gertrudes culpada.

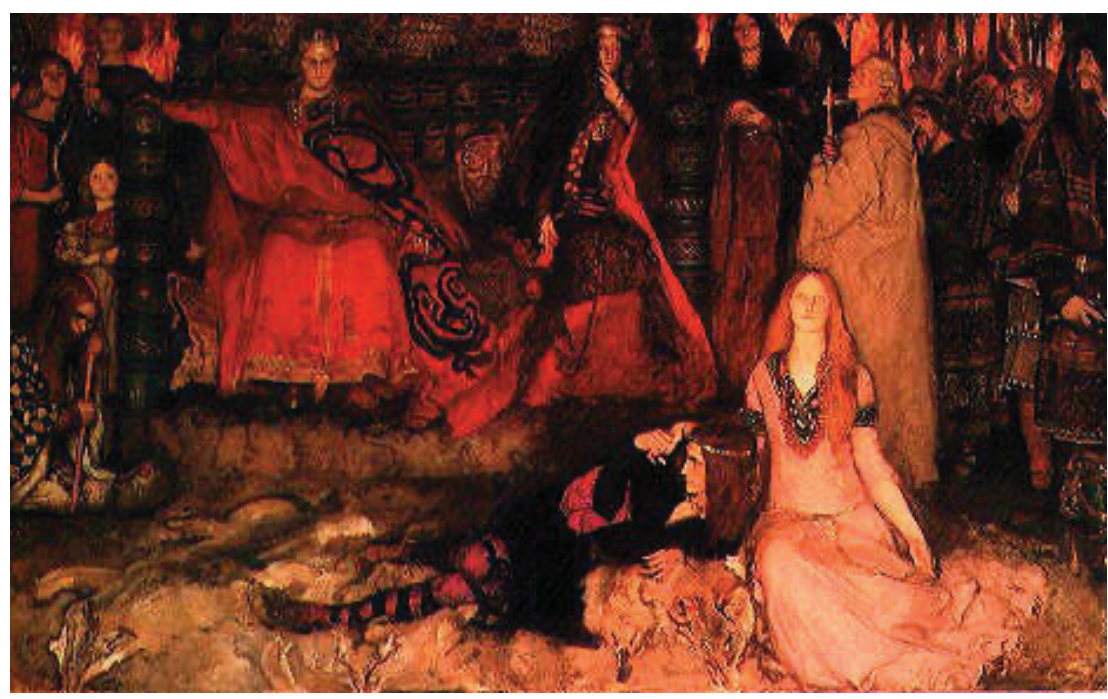

FIGURA 2: Hamlet, de Edwin Austin Abbey (1897). Óleo sobre tela-61.25 'x 96.5', The Edwin Abbey. Memorial Collection, Yale University, New Haven, Connecticut, EUA.

Fonte: https://www.wikiart.org/pt/edwin-austin-abbey/the-play-scene-in-hamlet-1897

Estudar essa obra comparando a cena teatral por meio das duas pinturas evidencia quão versátil e sujeita a interpretações a peça demonstra ser. Embora não haja no texto nenhuma pista da culpa de Gertrudes, os artistas, com sua arte, conseguem expor seu ponto de vista. Os alunos se mostraram bastante entusiasmados com as possibilidades de interpretação do texto escrito por meio das pinturas.

\section{Poetas canônicos e contemporâneos}

O estudo de muitos outros autores, não só os canônicos, mas também escritores das literaturas das colônias, foi realizado também sob esse novo enfoque, com muito sucesso, aprovação e interesse por parte dos alunos. É o caso de um poeta canônico da literatura inglesa, William Blake, e um poeta nigeriano contemporâneo, não canônico, Niyi Osundare, abordados em aulas da disciplina acima mencionada. Ambos criaram poemas de resistência, 
às vezes mais velada, outras vezes mais explícita, mas frequentemente ligados a obras de arte visuais.

\section{William Blake}

Como tinha grande talento verbal e visual, William Blake (1757-1827) começou a combinar palavras e imagens em uma nova forma: a impressão de iluminuras. Entre essas, destaca-se a placa 39, "Sick Rose", composta de um pequeno poema inserido numa lâmina, com desenhos que o emolduram ${ }^{6}$. Neste curto e lindo poema William Blake usa conscientemente a personificação onde qualidades humanas são atribuídas à "rosa" e ao "verme". Os sentidos morais, emocionais e sensuais são simbolizados: a rosa fica doente e o verme tem o poder de "fazer amor" e "encontrar o leito". Superficialmente o poema trata de uma rosa e um verme, mas é óbvio que existe um significado escondido. O verme pode simbolizar o mal, sugerido também pelas palavras: sick, worm, night, howling storm, dark, secret, destroy. Oferece ainda ideias de luxúria, pecado, destruição, corrupção e morte. Já a rosa sugere pureza, inocência, beleza, ignorância. A rosa inocente é arruinada pelo verme experiente.

As situações descritas são simbólicas, significam mais do que se pode inferir e o poeta usa o contraste como um recurso poético para transmitir sua ideia.

QUADRO 2: A Rosa Doente, poema de William Blake

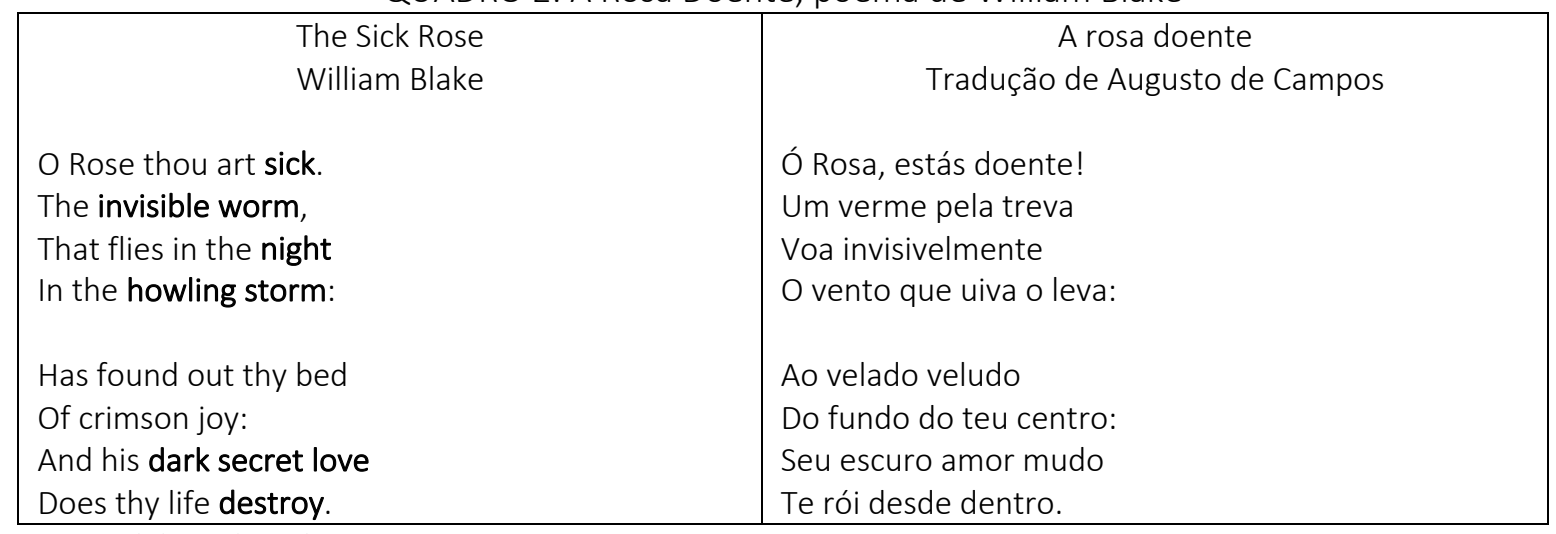

Fonte: elaborado pela autora.

\footnotetext{
${ }^{6}$ Uma análise mais completa desse poema encontra-se no artigo de minha autoria, intitulado "'A rosa doente' dos tempos modernos", publicado no Letras: Revista do Programa de Pós-graduação em Letras da Universidade Federal de Santa Maria, n. 51, dez 2015, p. 71-82.
} 
No poema, expresso de forma concisa, a voz lírica dirige-se a uma rosa, doente por ter um verme invisível penetrado em seu leito de "alegria rubra" [of crimson joy]. A rosa pode simbolizar o amor terreno, em oposição ao espiritual, que se torna também doente quando infectado pelo materialismo do mundo. Mas o leito de alegria rubra pode conotar também uma imagem sexual. É o "amor sombrio e secreto" [his dark secret Love] que destrói a vida da flor, sugerindo algo pecaminoso e inominável.

À primeira leitura, o poema parece bastante simples. Mas essa aparente simplicidade nos engana, pois muitas de suas palavras têm um duplo sentido ou são ambíguas e a moldura que o circunda ainda adiciona vários significados.

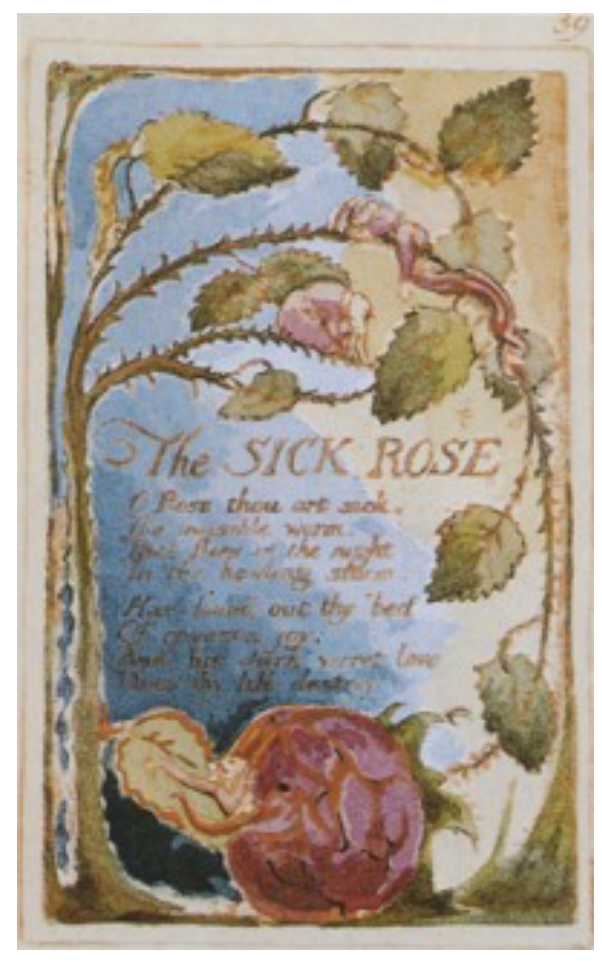

FIGURA 3: Plate 39. Blake, William. Songs of Innocence and of Experience, copy AA, Object 391826 (The Fitzwilliam Museum).

Fonte: $\quad$ https://commons.m.wikimedia.org/wiki/File:Songs_of_Innocence_and_of_ Experience,_copy_AA,_1826_(The_Fitzwilliam_Museum)_object_39_The_Sick_Rose.jpg

A página do poema tem a borda iluminada na qual podem-se ver três botões de rosa. Do primeiro, ainda fechado, emerge a figura de uma mulher com os braços estendidos; o segundo botão, já murcho, confunde-se com a imagem de uma mulher de joelhos, em atitude de dor ou de arrependimento. Já o terceiro, totalmente destruído, mistura-se ao corpo 
dilacerado de uma mulher. Os três podem significar o ciclo de uma doença: o verme penetra a rosa, instala-se nela e, por fim, a destrói, sugerindo, portanto, o ciclo da morte.

Muito já se estudou sobre essa lâmina que pode ser lida tanto como uma parábola dos efeitos perniciosos da repressão sexual quanto como uma discussão radical que celebra a energia sexual contra uma doutrina repressiva, considerações essas que se referem a elementos intrínsecos ao poema e à ilustração que o acompanha.

Entretanto, Jon Mee (1998), em sua análise, amplia esse contexto, insinuando que "The Sick Rose" seja também um sinal dos tempos, um diálogo com a história e uma afirmação sobre o estado corrupto da nação. Isso permite ler o poema também como uma reação à situação cultural específica de Blake: sua voz que associava a rosa com a "rosa da Inglaterra" ou rosa dos Tudors.

Para ler o poema como um texto que dá suporte à ressonância histórica, o crítico referiu-se a dois poemas satíricos escritos para um jornal radical da época. Destinavam-se a criticar o jornalista George Rose, um dos secretários do Tesouro que fora acusado de "subsidiar jornais, atrair escritores para escrever panfletos e comprar votos, tudo com dinheiro do tesouro" ${ }^{\prime 7}$. Na análise de Mee, a associação rosa/nação tem a ver com o episódio de Rose. Para Blake, a (R)osa [numa alusão a George Rose] seria o primeiro signo da corrupção dos tempos da política. Seu crime não seria uma contravenção individual, mas emblemática de uma corrupção muito maior, um veneno invisível que abria caminho em direção ao corpo (político).

Nos escritos do panfleto que se refere ao episódio de George Rose, as palavras "secret influence" [influência secreta] e "invisible corruption" [corrupção invisível] nos remetem ao "invisible worm" e ao "dark secret love" do poema de Blake. A linguagem usada na controvérsia sobre o jornalista pode ter influenciado Blake mas o paralelo com a linguagem do poema mostra-se ainda mais contundente quando o autor se refere ao fato de que o governo enviou "agentes do tesouro, com veneno nos bolsos, para destruir cada faísca de liberdade que eles pudessem encontrar e fazer voar pelos ares os botões entreabertos da

\footnotetext{
${ }^{7}$ Minha tradução do original: “... he subsidized newspapers, engaged writers, contracted for pamphlets (...) purchased votes (...) all with Treasury money” (apud MEE, p. 113).
} 
integridade ${ }^{8 \prime}$. A mulher que escapa do botão no desenho de Blake pode ser identificada com a figura da liberdade que abandona a rosa da Inglaterra, permitindo que o poema se configure como uma visão da corrupção da sociedade contemporânea.

Na avaliação da aula pelos alunos, concluiu-se que o estudo desse poema em suas características intrínsecas associadas à análise da obra visual, mas também em seu contexto, contribuiu para um melhor entendimento da obra, além de fornecer pistas para as razões pelas quais o escritor escolheu o tema e o adaptou para o seu momento histórico.

\section{Niyi Osundare}

Niyi Osundare é um dos mais expressivos poetas nigerianos da contemporaneidade, uma das vozes africanas mais notáveis. Tornou-se reconhecido pelo seu talento em falar a verdade ao poder, mesmo às custas de grande coragem. Seu poema, "Berlin 1884-5", fala da ferida causada pela Partilha da África, fato histórico resultante da industrialização do continente europeu no século XIX, quando o território africano tornou-se objeto de interesse para as potências europeias. Denominado Conferência de Berlim, o encontro entre as nações interessadas se propunha a uma missão civilizatória, mas seu verdadeiro objetivo era a ocupação e a divisão dos territórios africanos entre as nações europeias. Essa reunião representou um enorme surto neocolonialista tendo, como consequência, o que chamamos de Partilha da África (Scramble for Africa) em que os europeus, ao afirmarem arbitrariamente seus interesses nas colônias, romperam fronteiras e agrupamentos étnicos tradicionalmente estabelecidos, causando problemas gravíssimos e conflitos entre os povos africanos.

\footnotetext{
${ }^{8}$ Minha tradução do original: "Treasury Agents, with poison in their purses, to destroy every spark of freedom they may meet, and to blast the opening blossoms of integrity" (apud MEE, p. 116).
} 
QUADRO 3: "Berlin 1884", poema de Nyi Osundare

\begin{tabular}{|c|c|}
\hline Berlim 1884-5 & Berlim 1884-5 (tradução minha) \\
\hline I looked round for vendors of my own past, & $\begin{array}{l}\text { Procurei em volta pelos vendedores do meu } \\
\text { passado }\end{array}$ \\
\hline For that Hall where, many seasons ago, & Por aquele lugar onde, há muito tempo, \\
\hline ed up like a juicy mango & Meu continente foi fatiado como manga suculenta \\
\hline To & amainar a disputa entre irm \\
\hline the rift & Procurei pela faca que desferiu o golpe. \\
\hline & \\
\hline The & A ar \\
\hline o put & edoria dos poderosos que plantaram \\
\hline The & 0 \\
\hline The cruel arrogance of empire, & A arrogância cruel do Império, \\
\hline $\begin{array}{l}\text { Of kings/queens who laid claim to rivers, to } \\
\text { mountains, }\end{array}$ & $\begin{array}{l}\text { Dos reis/rainhas que se apoderaram de rios e } \\
\text { montanhas }\end{array}$ \\
\hline $\begin{array}{l}\text { To other peoples and other gods and other } \\
\text { histories }\end{array}$ & De outros povos, outros deuses e outras histórias. \\
\hline $\begin{array}{l}\text { And they who went to bed under one } \\
\text { conqueror's flag, }\end{array}$ & $\begin{array}{l}\text { E aqueles que dormiram sob a bandeira de um } \\
\text { colonizador }\end{array}$ \\
\hline $\begin{array}{l}\text { Waking up the next beneath the shadows of } \\
\text { another }\end{array}$ & Acordando no dia seguinte à sombra de outra \\
\hline $\begin{array}{l}\text { Their ears twisted to the syllable of alien } \\
\text { tongues }\end{array}$ & $\begin{array}{l}\text { Tiveram os ouvidos adaptados ao som das línguas } \\
\text { estrangeiras }\end{array}$ \\
\hline pats & Can \\
\hline Ter & Territórios de \\
\hline $\begin{array}{l}\text { Oh that map, that knife, those contending } \\
\text { emperors }\end{array}$ & $\begin{array}{l}\text { Oh! Aquele mapa, aquela faca, aqueles monarcas } \\
\text { rivais }\end{array}$ \\
\hline These bleeding scars in a Continent's soul, & $\begin{array}{l}\text { Essas cicatrizes sangrentas na alma de um } \\
\text { continente }\end{array}$ \\
\hline Insist & Insistindo em um milênio de cura. \\
\hline
\end{tabular}

Fonte: elaborado pela autora.

Nesse poema, Niyi Osundare critica a partilha da Africa, referindo-se àqueles que "venderam seu passado e fatiaram suas terras", e menciona tanto as mãos que "seguraram a faca que cindiu seu país" quanto aqueles que puseram "o mapa antes do homem". Condena ainda a arrogância cruel do Império e lamenta as feridas na alma do continente que, em agonia, ainda insiste na cura.

Esse triste episódio tem inspirado muitos outros poetas e também artistas contemporâneos, como o nigeriano Yinka Shonibare, que se diz um ser híbrido e usa sua arte como resistência. Sua obra, visualmente versátil, engloba pinturas, filmes fotografias e instalações, verdadeiras esculturas em fibra de vidro, que apresentam figuras humanas em tamanho natural. O material usado parece simples, mas existe muito mais por trás dele. A arte de Shonibare contém referências de todo o mundo e combina detalhes que alcançam 
séculos. Entre as questões globais contemporâneas exploradas pelo artista estão a escassez de água no planeta, a mudança climática e as questões raciais e de classes.

Uma de suas instalações, The Scramble for Africa (2003) reimagina dramaticamente a Conferência de Berlim.

As posturas teatrais das figuras acéfalas (estilo do autor) insinuam as intrigas políticas e a falta de escrúpulos responsáveis pela disputa caótica, que Bismark tentava solucionar, entre os europeus. The Scramble for Africa é fundamental para simbolizar a exploração da Inglaterra vitoriana e sua expansão territorial, legado do Colonialismo que Shonibare procura explorar. Essa obra se constitui de um grande mapa da Africa sobre uma mesa em volta da qual se amontoam os manequins/estadistas tentando avidamente delimitar o objeto de suas reivindicações. Aqui verdadeiramente o mapa teve prioridade sobre o homem.
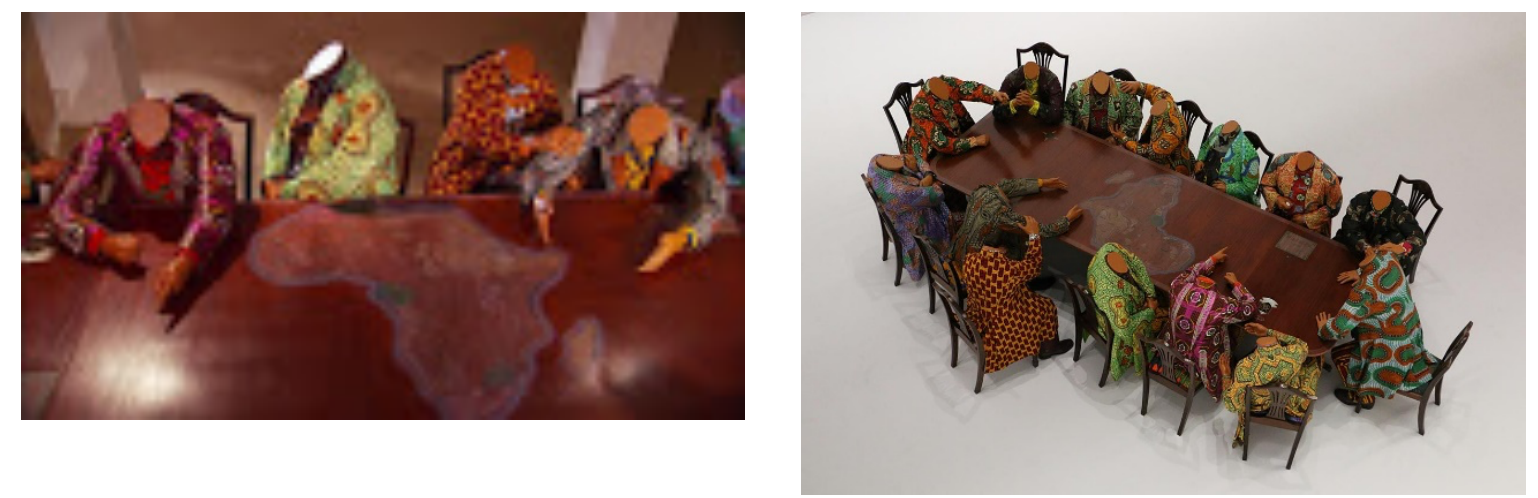

FIGURA 5: "Scramble for Africa", de Yinka Shonibare (2003). Instalação em tamanho natural composta por 14 manequins em fibra de vidro, 14 cadeiras, 1 mesa, batik em algodão. The Pinnell Collection, Dallas, Texas, EUA.

Fonte: https://africa.si.edu/exhibits/shonibare/scramble.html

Segundo os alunos, a análise do poema, associada ao estudo da obra do artista nigeriano em suas características que sutilmente denunciam o colonialismo, promoveu uma compreensão maior do poema, mas também dos elementos que subjazem a expressões artísticas como essa. 


\section{Considerações finais}

Os exemplos de análise ilustrados aqui comprovam que as obras literárias têm sido traduzidas/adaptadas com bastante criatividade para várias mídias e para outras formas de discurso. Demonstram ainda que, mesmo que sejam criadas inicialmente em sistemas verbais, podem ser estudadas/abordadas/analisadas em conjunção com suas adaptações/traduções/ transposições em outros sistemas midiáticos. Esse tipo de estudo facilita a compreensão tanto das razões pelas quais as obras foram criadas quanto do entendimento da visão de mundo que, na voz de seus reescritores, está por trás de suas traduções.

Esses exemplos demonstram ainda que a leitura de textos de literaturas de expressão inglesa (e, por extensão de outras literaturas) pode ser feito em conjunção com o estudo de peças artísticas a eles relacionadas com grande proveito e mesmo prazer para os alunos.

\section{Referências}

BLAKE, William. The Sick Rose. Songs of Innocence and of Experience, copy AA, Object 39 1826 (The Fitzwilliam Museum) published by the The William Blake Archive. Ed. Morris Eaves, Robert N. Essick, and Joseph Viscomi. Disponível em: http://en.wikipedia.org/wiki/The_Sick_Rose\#/media/File:Songs_of_innocence_and_of_experi ence,_page_39,_The_Sick_Rose_(Fitzwilliam_copy).png. Acesso em: 27 abr. 2016.

DINIZ, Thaïs F. N. "A Rosa Doente" dos tempos modernos. Letras: Revista do Programa de pós-graduação em Letras da UFSM, v. 27, n. 51, p. 71-81, jul.-dez. 2015. DOI: https://doi.org/10.5902/2176148523547

DINIZ, Thaïs F. N. Nova luz sobre Heart of darkness: "The scramble for Africa", de Yinka Shonibare. Letras \& Letras, v. 27, n. 2, 30 mar. 2012

GREENBLAT, Stephen. The interart moment. In: LAGERROTH, Ulla-Britta; LUND, Hans; HEDDING, Erik (Ed.). Interart Poetics: Essays on the Interrelations of the Arts and Media. Amsterdam: Rodopi, 1997.

HOEK, Leo H. A transposição intersemiótica: por uma classificação pragmática. Trad. Márcia Arbex et al. In: ARBEX, Márcia. Poéticas do visível: ensaios sobre a escrita e a imagem. Belo Horizonte: FALE/UFMG, 2006. p. 167-220.

LAWRENCE, William Witherle. The play scene in Hamlet. The Journal of English and German Philology, v. 18, n. 1, p. 1-22, jan. 1919. 
MEE, Jon. The "insidious poison of secret Influence": A new historical context for Blake's "The Sick Rose". Eighteenth-Century Life, v. 22, n. 1, p. 111-122, fev. 1998.

OSUNDARE, Nyvy. "Berlin 1884/5". Disponível em: https://www.lyrikline.org/en/poems/berlin-18845-12576. Acesso em: 02 mar. 2020.

RAJEWSKY, Irina. Intermidialidade, Intertextualidade e "remediação": uma perspectiva literária sobre a intermidialidade. Trad. Thaïs Diniz e Eliana Lourenço Lima Reis. In: Diniz, Thaïs F. N. (Org.). Intermidialidade e estudos interartes: desafios da arte contemporânea. Belo Horizonte: Editora UFMG, 2012. p. 15-45. 